\title{
Dynamic characteristics of old railway steel bridges in Egypt
}

\author{
Maha M. Hassan ${ }^{1,{ }^{*}}$ and Hussein H. Abbas ${ }^{2}$ \\ ${ }^{1}$ Structural Engineering Department, Cairo University, Giza, Egypt \\ ${ }^{2}$ Structural Engineering Department, Al-Azhar University, Cairo, Egypt
}

\begin{abstract}
Dynamic response of existing railway bridges is influenced by many factors including structural properties, railway traffic speed, and train-to-bridge frequency. Excessive vibrations cause passengers' discomfort, rail elements deterioration, higher derailment risks, fatigue deformation problems, stress amplification, and eventually high maintenance costs. In such cases, applied remedies include limiting traffic speed or changing bridge mass or stiffness. Traffic induced vibrations can also be mitigated by enhancing structural damping through application of Tuned Mass Dampers. Egypt has one of the oldest railway transportation network with several steel bridges crossing the Nile River, in addition to several canals. In a running project, dynamic properties of selective bridges on the Egyptian railway networks infrastructures are investigated through extensive field testing. The considered bridges cover a wide range of structural properties including simply-supported and continuous bridges, spans ranging between 40 to $90 \mathrm{~m}$, single and double track lines, and open timber bridges. Field tests results are studied; hence, key factors affecting bridge dynamic characteristics are discussed and highlighted. Moreover, results are compared with those extracted from finite element analyses. The project aims at evaluating the possibility of excessive vibration problems while considering different values of train velocities. In the current study, focus is given to two example bridges. Field and numerical results are exhibited and discussed. Eventually, possibility of excessive vibration problems are determined considering different values of train velocities. It was observed that available formulas in current design codes do not capture warping and torsional modes that present fundamental modes for truss bridges. In addition, existing railway bridges do not satisfy serviceability limit states when considering high speed trains.
\end{abstract}

\section{Introduction}

Dynamic properties of steel bridges affect the railway transportation network performance. Induced vibrations due to train passages over open timber steel bridges can result in discomfort to passengers. In addition, excessive vibrations can result in increasing the impact factor values compared to the ones considered in design. Historically, the serviceability deflection limits were used as a sign for any expected undesirable motion.

\footnotetext{
* Corresponding author: mahamoddather@eng.cu.edu.eg
} 
However, undesirable vibrations may be linked to several parameters including bridge geometry, speed of trains, and specifications of bearings. Building simulation models that can accurately capture the effect of these parameters is complicated. Hence, field tests are considered the most reliable method for determining the dynamic characteristics of bridges. A steel bridge is a massive and elastic structure and, as such, is able to vibrate in a number of different ways, with different frequencies. In a structure as complex as a bridge, the possible frequencies are so numerous and varied that the noise emitted may not indicate a dominant mode; and, the important vibrations, which strain the main members and have natural frequencies approaching those of any probable periodic forces acting on the structure, may lie below the audible range.

In addition to human comfort limits, dynamic properties influence the response of bridges under seismic loads. Dynamic properties of steel bridges have been extensively investigated due to its effects on the structural response of bridges. Different researchers focused on building reliable models that can provide accurate predictions for the dynamic response of bridges [1-3]. Different parameters were considered including speed of train, train-to-bridge frequency, mass and span ratios, as well as bridge damping. Field testing was also employed to determine mode shapes and associated natural frequencies [4-6]. These properties were used to pinpoint defects and damage in the investigated bridges through damage indices [7-10].

The railway transportation network in Egypt incorporates steel bridges crossing the Nile River in addition to several canals. Some of these bridges are constructed since over 100 years. During such period, the design of steel bridges was governed by the dead and live loads in addition to wind loads. Impact factors were commonly applied to the live loads in order to account for the uncertainties related to the dynamic moving loads. Besides the check on stresses within members, deflection limitations were imposed to limit bridge vibration under the different load effects. In this paper, results of field tests on two steel open-timber truss bridges with different systems are presented. The study focuses on the dynamic properties of the considered bridges and relates them to the probability of induced vibrations. The work in this paper represents a research effort exerted to reach a formula relating the bridge dimensioning and system for open timber through truss bridges to their dynamic properties based on the gathered data and the performed analyses. The aim of the current paper is to focus on the dynamic properties of two bridges through both experimental and analytical studies.

\section{Description of bridges}

In Egypt, an extensive assessment campaign has been initiated for a large group of steel railway bridges [11-13]. Part of the assessment includes performing dynamic tests which are used to determine the fundamental mode shapes and frequencies of the studied bridges. These were mainly used to validate the built finite element models. In the following sections, focus will be given to dynamic test and finite element results for two example bridges: Marazek and Mansoura Bridges. These bridges were chosen as they represent two different structural systems and usage of bridge. Figures 1 and 2 show a general view of the two studied bridges. Marazek bridge was constructed between 1955-1959. The bridge is a combined railway and roadway bridge over the Nile River near Helwan City. It consists of 9 equal spans with a total length of $810 \mathrm{~m}$. Each three successive spans are continuous. The bridge cross section includes one railway track in addition to a traffic lane and two sidewalks. Mansoura bridge was constructed in 1913. The bridge consists of 4 spans representing simple steel open floor truss. Each span is $68.8 \mathrm{~m}$ length with a total length of $280 \mathrm{~m}$. At the time of its construction, the bridge had double track lines. The bridge has three fixed simple spans and one movable (swing type) bay. The main structural system for 
each bay is a simply supported riveted truss with variable depth: $5.0 \mathrm{~m}$ at support and $9.0 \mathrm{~m}$ at middle of the bay. The main trusses are connected with transverse secondary beams, horizontal upper and lower bracing system, and lower beams. Figures 3 and 4 show the general layout of the bridge.

The two bridges are chosen to present different structural systems, different span length, and different degree of indeterminacy. Different tests were performed on both bridges. The current paper will focus on dynamic test procedures and their results.

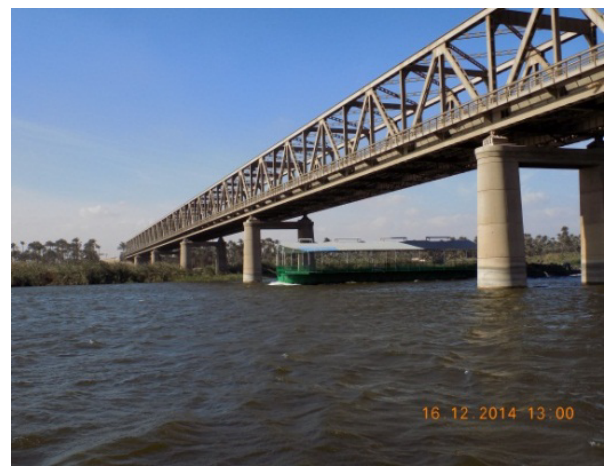

Fig.1. Marazek Bridge, 1959.

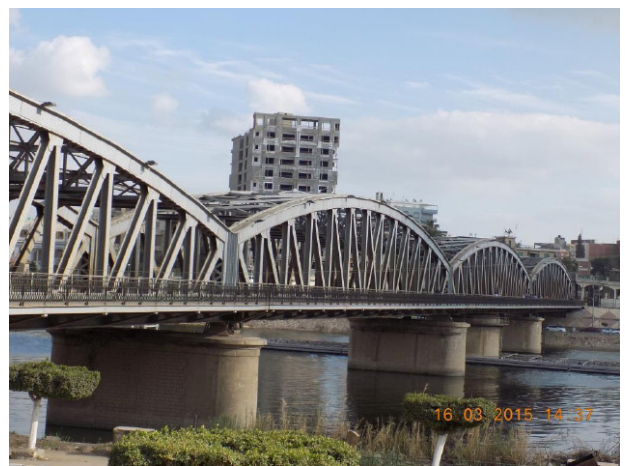

Fig.2. Mansoura Bridge, 1913.

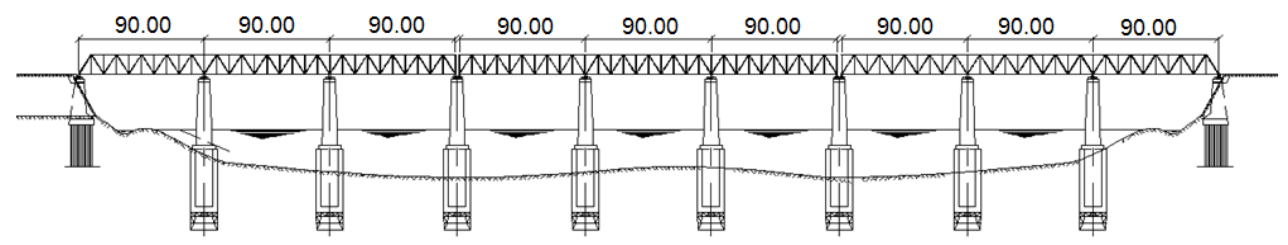

Fig.3. General Layout of Marazek Bridge.

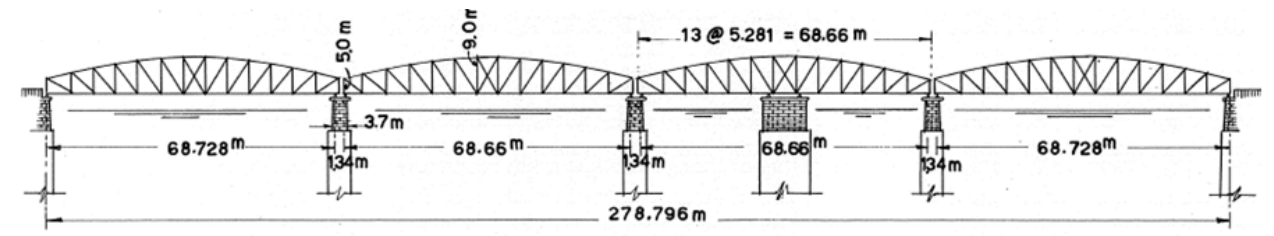

Fig. 4. General Layout of Mansoura Bridge.

\section{Dynamic test procedure and results}

The two bridges were subjected to passage of train as an excitation method in order to facilitate observing the investigated modes (Figure 5). Accelerometers are attached to the bridge at suitable arrangement to capture the shape of the most relevant modes. Measurements were recorded for 120 seconds using sampling rate of 200 reading/second. Readings were also taken three times in order to consider average of results. Figure 6 shows the instrumentation and data acquisition system. Acceleration for Mansoura bridge are exhibited in Figure 7 after removing the part recorded during passage of train in order to preclude the influence of the large mass of the train.

Table 1 summerizes the main dimensional properties of the considered two bridges. Meanwhile, Table 2 lists the concluded frequencies from the performed tests. For Mansoura 
bridge, it was observed that the observed acceleration at bottom chord level are higher than the vertical movement. It was also generally observed that the main movement of the bridge are combined lateral movement at upper and lower bracing levels combined with torsional movement. For Marazek bridge, the observed modes included lateral mode followed by flexural mode then several combined flexural and torsional modes.
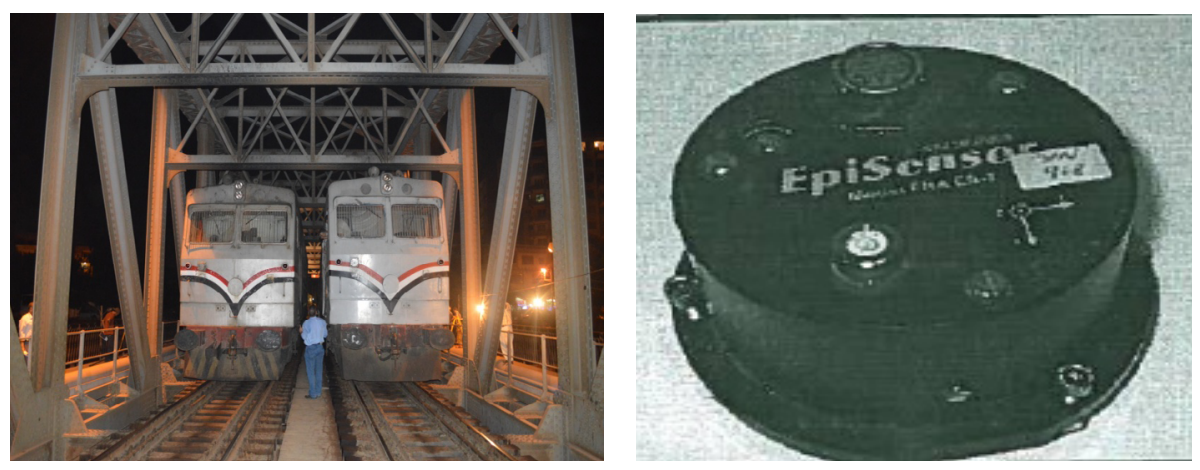

Fig. 5. Mansoura Bridge Dynamic Test: Excitation Trains and Used Accelerometer.

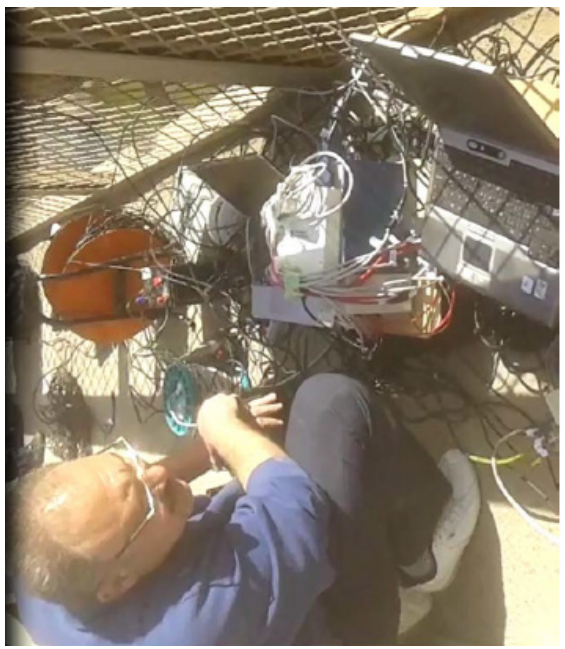

Fig. 6. Data Acquisition System and Registration of Data.

Table 1. Geometric Properties of Studied Bridges.

\begin{tabular}{|c|c|c|c|c|l|}
\hline Bridge & $\begin{array}{c}\text { Construction } \\
\text { Year }\end{array}$ & $\begin{array}{c}\text { Span } \\
(\mathbf{m})\end{array}$ & $\begin{array}{c}\text { Height } \\
(\mathbf{m})\end{array}$ & $\begin{array}{c}\text { Width } \\
(\mathbf{m})\end{array}$ & $\begin{array}{c}\text { Structural } \\
\text { System }\end{array}$ \\
\hline Mansoura Bridge & 1913 & 68.66 & $5-10$ & 8.9 & Simply Supported \\
\hline Marazek Bridge & 1959 & 90.00 & 11 & 12.5 & $\begin{array}{l}\text { Continuous }-3 \\
\text { spans }\end{array}$ \\
\hline
\end{tabular}




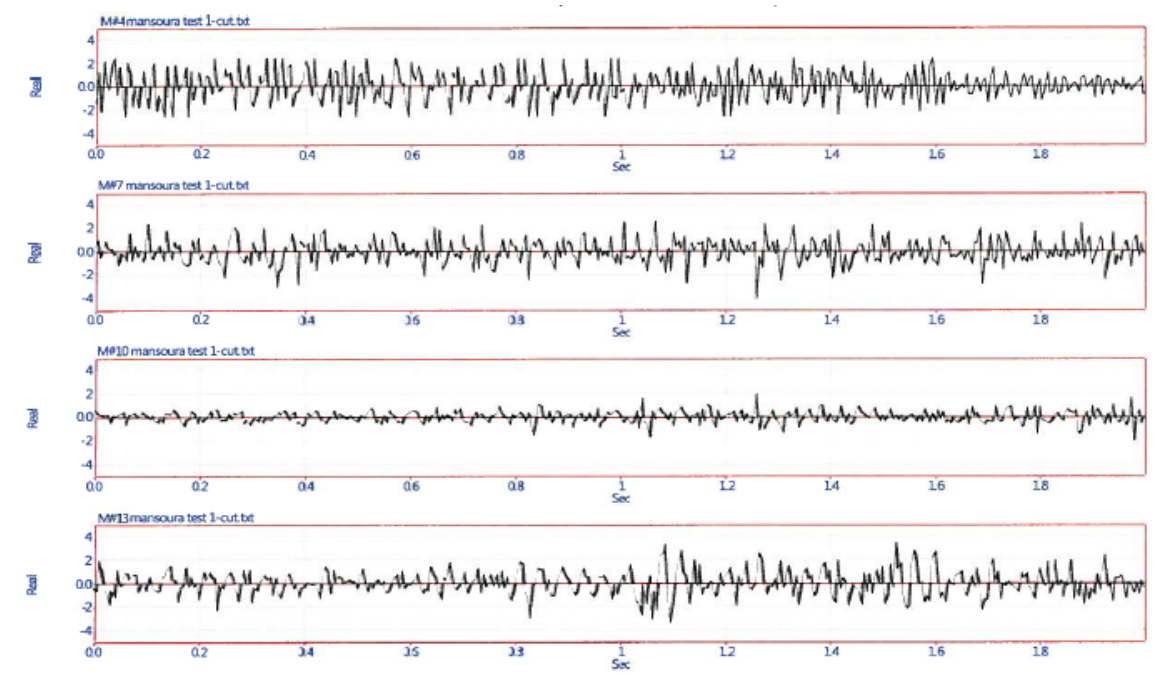

Fig. 7. Samples of Registered Acceleration.

Table 2. Frequencies (Hz) of Measured Modes.

\begin{tabular}{|c|c|c|c|c|}
\hline Mode & $\begin{array}{c}\text { Mansoura } \\
\text { Bridge }\end{array}$ & Description of Modes & $\begin{array}{c}\text { Marazek } \\
\text { Bridge }\end{array}$ & Description of Modes \\
\hline $\mathbf{1}$ & 2.030 & $\begin{array}{l}\text { Lateral Movement at } \\
\text { Upper Level + Torsion }\end{array}$ & 0.634 & Lateral Movement \\
\hline $\mathbf{2}$ & 3.980 & $\begin{array}{l}\text { Lateral Movement at } \\
\text { Lower Level + Torsion }\end{array}$ & 1.950 & Flexural Movement \\
\hline $\mathbf{3}$ & ---- & --- & 2.260 & $\begin{array}{c}\text { Combined Flexural }+ \\
\text { Torsional Movement }\end{array}$ \\
\hline $\mathbf{4}$ & ---- & --- & 2.760 & $\begin{array}{c}\text { Torsional Movement } \\
\mathbf{5}\end{array}$ \\
\hline $\mathbf{6}$ & ---- & --- & 3.600 & $\begin{array}{c}\text { Combined Flexural + } \\
\text { Torsional Movement }\end{array}$ \\
\hline & --- & & 7.690 & $\begin{array}{c}\text { Second Flexural } \\
\text { Movement }\end{array}$ \\
\hline
\end{tabular}

\section{FE models}

Three dimensional models were built using SAP 2000 [14] program for the two studied bridges. Figure 8 shows the general layout of the models. Sectional properties as deduced from the available as-built drawings are defined for the different frame elements. For Mansoura bridge, several members were added to the bridge during repair procedures applied through the bridge service life. These modifications were accounted for in the FE model [15]. Connections between truss members and different floor beams are simulated using rigid and pinned connections. Models are built considering the sectional properties extracted from the as-built drawings or measured during the visual inspection phase. Frame 
elements are used to simulate the different bridge components. Rigid and pinned joints are used to simulate the connection at the truss and floor beam levels as per the observed details. Model considered in the current study accounts for all the applied repair procedures along the service life of the bridge.

For both bridges, the resulting modes coincide with the experimentally observed values; however, for Marazek bridge, large difference in frequency value is observed. Source of deviation are under investigation. Possible sources include the defects observed at one of the bearings and loss of one of bridge verticals due to a derailment accident of a train in 2003. It is also observed that frequency for Mansoura bridge is higher than that of Marazek bridge. This may be attributed for the larger depth of Marazek bridge which leads to higher stiffness. In addition, the continuity of Marazek bridge would increase its stiffness.
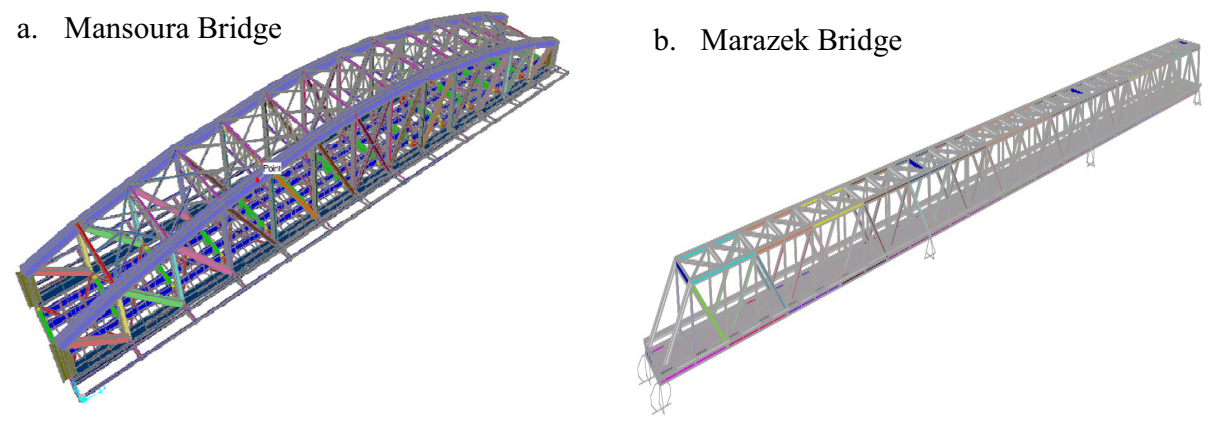

Fig. 8. FE Models for Mansoura and Marazek Bridges.

The Egyptian code for bridges [12] specifies a range for acceptable bridge frequencies according to the following:

Upper Bound: $\mathrm{n}_{\mathrm{o}}=94.76 \mathrm{~L}^{-0.748}[\mathrm{~Hz}]$

Lower Bound:

$\begin{array}{ll}4 \mathrm{~m} \leq \mathrm{L} \leq 20 \mathrm{~m} & \mathrm{n}_{\mathrm{o}}=80 / \mathrm{L}[\mathrm{Hz}] \\ 20 \mathrm{~m}<\mathrm{L} \leq 100 \mathrm{~m} & \mathrm{n}_{\mathrm{o}}=23.58 \mathrm{~L}^{-0.592}[\mathrm{~Hz}]\end{array}$

As can be seen, the formula only relates the frequency only to bridge length regardless of other influencing factors. In addition, these formulas consider that the governing mode is vertical flexural mode. Meanwhile, the Egyptian code [16] does not provide formulas for torsional modes. Table 4 summerizes the resulting values considering effective spans for the considered bridges. As can be seen, the measured values do not fall within the calculated range. Moreover, the percentage of error is calculated considering the average of the two bound values and the flexural mode frequency. It can be noted that code formula does not capture bridge performance. Hence, for truss bridges, Egyptian code requires performance of dynamic analysis to evaluate dynamic bridge performance.

Table 3. Frequencies (Hz) of Measured Modes.

\begin{tabular}{|c|c|l|c|c|}
\hline Mode & $\begin{array}{c}\text { Mansoura } \\
\text { Bridge }\end{array}$ & \multicolumn{1}{|c|}{ Description of Modes } & $\begin{array}{c}\text { Marazek } \\
\text { Bridge }\end{array}$ & $\begin{array}{c}\text { Description of } \\
\text { Modes }\end{array}$ \\
\hline $\mathbf{1}$ & 2.433 & $\begin{array}{l}\text { Lateral Movement at Upper } \\
\text { Level + Torsion }\end{array}$ & 1.780 & Lateral Movement \\
\hline $\mathbf{2}$ & 4.049 & $\begin{array}{l}\text { Vertical Flexural + Local } \\
\text { Deformation of Upper Portal } \\
\text { Bracing Mode Shape }\end{array}$ & 2.517 & Flexural Movement \\
\hline
\end{tabular}




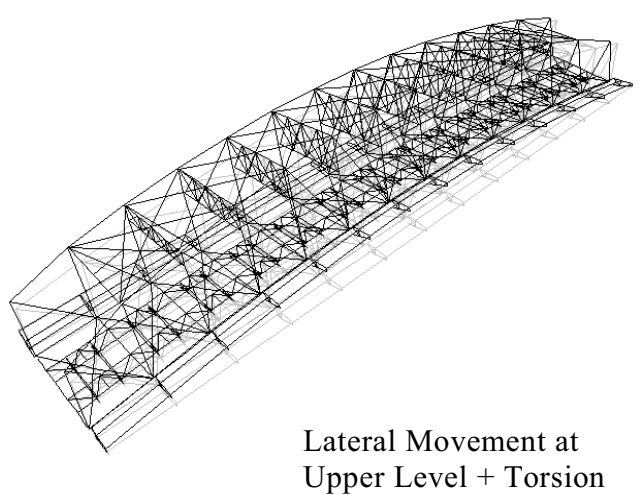

a. First Mode Shape - Mansoura Bridge.

Lateral Movement

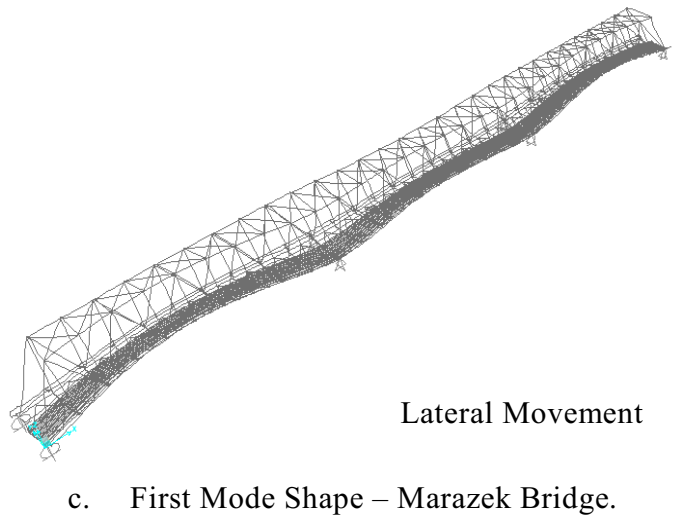

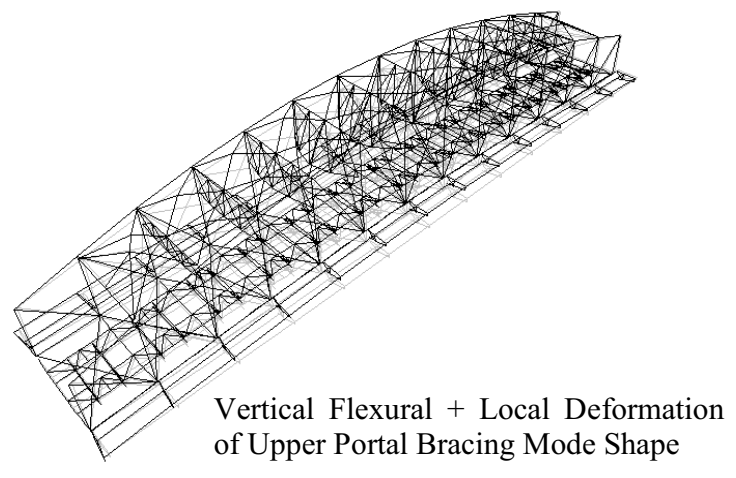

b. Second Mode Shape - Mansoura Bridge.

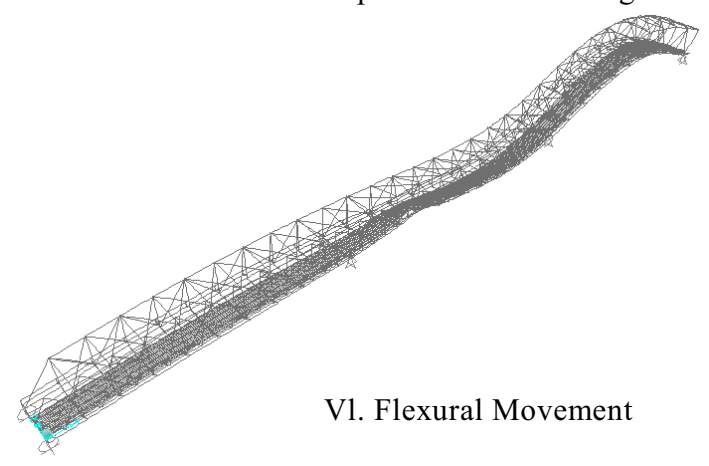

d. Second Mode Shape - Marazek Bridge.

Fig. 9. Calculated Mode Shapes

Table 4. Calculated Upper and Lower Frequencies using Egyptian Code Formulas [16].

\begin{tabular}{|c|c|c|c|}
\hline Frequency [Hz] & Mansoura Bridge & Marazek Bridge & $\begin{array}{c}\text { Percentage of Error } \\
\mathbf{( \% )}\end{array}$ \\
\hline Lower Bound & 1.907 & 3.949 & $27 \%$ \\
\hline Upper Bound & 1.875 & 3.867 & $14 \%$ \\
\hline
\end{tabular}

Train velocity in Egypt usually ranges between $60-90 \mathrm{~km} / \mathrm{hr}$. The input frequency (ff) can be calculated according to the following:

$$
\mathrm{f}_{\mathrm{f}}=\mathrm{v} / 3.6 / \mathrm{D}[\mathrm{Hz}]
$$

Where:

$\mathrm{v}$ : Train speed $[\mathrm{km} / \mathrm{hr}]$

D: Characteristic wagon length (m)

For the used wagons in Egypt, the range of input frequencies is listed in Table 5.

Table 5. Input Frequency Range for Different Train Velocities.

\begin{tabular}{|c|c|c|c|c|}
\hline Train Velocity $(\mathbf{k m} / \mathbf{h r})$ & $\mathbf{9 0}$ & $\mathbf{8 0}$ & $\mathbf{7 0}$ & $\mathbf{6 0}$ \\
\hline Input Frequency Range $(\mathbf{H z})$ & $1.1-2.1$ & $0.9-1.9$ & $0.8-1.7$ & $0.7-1.4$ \\
\hline
\end{tabular}


In case bridge dynamic properties coincide or fall in ranges within these values, resonance phenomena may occur. Truss bridges are generally susceptible to undergoing transverse vibrations under resosnant conditions, leading to excessive vertical acceleration. This may lead to exceeding serviceability limit states and discomfort of users. Figure 10 shows the transmissibility ratio for Mansoura bridge while considering the flexural mode frequency. The frequency ratio for the different considered train velocities are plotted in order to evaluate the possibility of resnonace. As can be seen, the current structural systems does not allow for high speed velocities.

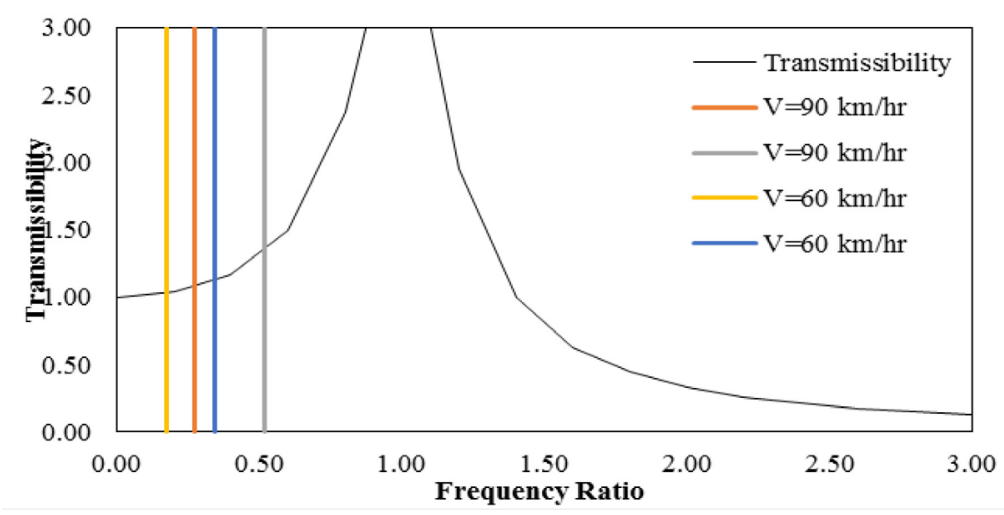

Fig. 10. Transmissibility versus Frequency Ratio for Mansoura Bridge.

\section{Conclusions}

Dynamic properties of two example bridges have been studied in the current work, both experimentally and analytically, in order to better understand the bridge dynamic properties and the influence of different parameters. This work is part of a comprehensive assessment campaign of a large group of steel bridges located along the railway network in Egypt. Focus is given to truss bridges with different spans and structural statistical systems. Truss bridges are generally susceptible to transversal lateral modes at the upper and lower bracing levels followed by vertical flexural mode shapes. Results were examined against formulas provided by local code provisions. These provisions link bridge fundamental frequency to its length regardless of its width or statical system. Meanwhile, formulas for torsional modes are not presented. In addition, input frequencies by current wagons are evaluated against bridge properties in order to assess probability of resonance phenomenon. Results are studied in order to deduce a suitable formula for calculating steel truss bridges, however, the discussion is beyond the scope of this paper.

The authors wish to express their sincere appreciation to the structural team at EHAF Consulting Office for the technical support during the inspection campaign including over 75 railway bridges. The authors also would like to acknowledge the support provided by the Egyptian National Railways (ENR).

\section{References}

1. M. Turek, C.E. Ventura, J. Centeno, B. Pandey, S. Huffman, In IOMAC: $3 r d$ International Operational Modal Analysis (2009)

2. P. Keller, C. Higgins, S.C. Lovejoy, J. Brdg. Eng. 20, 9 (2014) 
3. S.H. Ju, H.T. Lin, J. Eng. Struct. 25, 2, 241-250 (2003)

4. C. Gentile, Saisi, J. Constr. Build. Mat. 25, 3709-3720 (2011)

5. C.E. Ventura, J.C. Carvajal, E. Dascotte, In Dynamics of Bridges Conference Series: IMAC-XXVIII 5, 46-56 (2010)

6. M. Majka, M. Hartnett, J. Comp. Struct. 86, 6, 556-572 (2008)

7. K.C. Chang, C.W. Kim, J. Eng. Struct. 122, 156-173 (2016)

8. G. Yan, S.J. Dyke, A. Irfanoglu, J. Mech. Sys. Sign. Process. 28, 195-211 (2012)

9. S.C. Siriwardane, J. Case Stud. Eng. Fail. Analy. 4, 50-58 (2015)

10. M. Montazer, S.M. Seyedpoor, J. Shock Vib. (2014)

11. H.H. Abbas, M.S. Saleh, M.M. Hassan, In 2nd HBRC-ISHMII: Bridge Testing, Monitoring and Assessment, SHM19 (2016)

12. H.H. Abbas, M.S. Saleh, M.M. Hassan, In 2nd HBRC-ISHMII: Bridge Testing, Monitoring and Assessment, SHM20 (2016)

13. H.H. Abbas, M.S. Saleh, M.M. Hassan, In 2nd HBRC-ISHMII: Bridge Testing, Monitoring and Assessment, SHM21 (2016)

14. CSI (2003). SAP2000: Integrated Software for Structural Analysis and Design. Computers and Structures, Inc., Berkeley, CA, U.S.A.

15. H.H. Abbas, M.M. Hassan, In 19th IABSE Congress Stockholm: Challenges in Design and Construction of an Innovative and Sustainable Built Environment, 2502-2509 (2016)

16. ECP 207 (2015). The Egyptian Code of Practice for Loads and forces in bridges and intersections. Housing and building research center. Giza, Egypt: Building and Physical Planning. 